\title{
Meta-Analysis on Comparison of Therapeutic Effects of Different Treatment Methods on Multiple Rib Fractures
}

Hao Zhang ( $\nabla$ ctjd_zh@126.com )

Tianjin Xiqing Hospital

Ting Feng

Tianjin Xiqing hospital

Jie zhi Pei

Tianjin Xiqing Hospital

Research article

Keywords: rib fractures, flail chest, surgical intervention, conservative treatment, Meta-analysis

Posted Date: February 12th, 2020

DOI: https://doi.org/10.21203/rs.2.23361/v1

License: (1) (i) This work is licensed under a Creative Commons Attribution 4.0 International License.

Read Full License 


\section{Abstract}

Objective

The treatment of multiple rib fractures is worthy of consideration. A Meta-analysis on the surgical and conservative treatment of multiple rib fractures was carried out in this paper to explore the curative effect of these methods and provide some medical evidence.

Methods

Articles about randomized controlled trials (RCT) on the surgical and conservative treatment of multiple rib fractures were retrieved from the PubMed, Embase and Cochrane library databases, and were screened then to extract the data. The results were displayed by forest plots.

Results

This study included 5 articles and 337 cases which were divided into the surgical group (161 cases) and conservative group (176 cases). The Meta-analysis showed that differences between the two groups in respirator support time, intensive care unit (ICU) stay time, length of stay, and the incidence of pulmonary infection, chest wall deformity, chest tightness and breathlessness on exertion were statistically significant, and the differences between the two groups in the rate of tracheotomy and in-hospital mortality were not statistically significant.

Conclusion

The surgical treatment of multiple rib fractures can shorten the respirator support time, ICU stay time and length of stay, and reduce the incidence of pulmonary infection and chest disability, but this should be verified further by more randomized controlled trials. Key words: rib fractures; flail chest; surgical intervention; conservative treatment; Meta-analysis

\section{Background}

Multiple rib fractures are commonly seen in chest trauma, and one in every five patients with blunt chest trauma suffers from multiple rib fractures [1]. A special phenomenon called flail chest sometimes occurs when multiple rib fractures happen. Flail chest refers to the fracture of 3 or more than 3 ribs in adjacent parts at one side or two sides of the chest, leading to destruction of the thorax stability, softening of chest wall, and thus the paradoxical respiratory movement [2-3]. It often causes the lowering of respiratory efficiency of patients, then expiratory dyspnea, hypoxemia, and even respiratory distress syndrome, threatening the life of patients. Therefore, the treatment of multiple rib fractures is worth much attention.

How to treat rib fracture? It is a question worthy of consideration by thoracic and trauma surgeons. The thorax has relatively good stability, and it is usually considered that the rib fractures without flail chest are relatively stable and have little influence on the chest even if many ribs are broken. Some patients with 
severe flail chest are still treated with analgesia, chest bandage for fixation, backplate for fixation, rest in bed, bronchoscopy and aspiration of sputum, mechanical or artificial ventilation [4-5]. The treatment of rib fractures has changed with the rapid development of surgery, and especially, the studies in recent years have made positive and objective comments on the treatment effect of surgery [6-11], but applying surgical intervention in the treatment of rib fractures is still very controversial and challenging. Therefore, it is essential to establish proofs for this question by using evidence-based medicine method. There are studies that have systematically assessed and conducted Meta-analysis of the surgical and non-surgical treatment of rib fractures at present [12-14], but most of them are retrospective, and randomized controlled trials are absent. Although there are studies about randomized controlled trials [15], it is the goal of evidence-based medicine to update the results of these studies, include more randomized controlled trials, and arrive at more convincing results. Therefore, the significance of this paper is to include more high-quality studies that have been published continuously and provide more medical evidence for this question.

\section{Materials And Methods}

\section{Literature Retrieval}

Articles published from the establishment date of the PubMed, Embase and Cochrane library databases to December 2019 about the surgery and traditional treatment of multiple rib fractures were retrieved from these databases. The keywords included "surgery", "operative", "internal fixation", "conservative treatment", "non-surgical treatment", "rib fracture", "flail chest", and "randomized controlled trial", which were connected with "AND" or "OR".

\section{Inclusion and Exclusion Criteria}

Inclusion criteria: a. Object of this study were patients diagnosed as having multiple rib fractures after a variety of inspection; b. This study was a randomized controlled trial (RCT); $c$. The interventions for the surgical treatment group included thoracoscopy or thoracotomy, and those for the conservative treatment group included methods like chest bandage for fixation, rest in bed, sedation, and respiratory support. Exclusion criteria: a. Non-RCT studies; b. Personal operative experience, animal model tests, conference papers, summaries, and case reports; c. Studies without the control group (i.e. lacking the conservative treatment group or the surgical treatment group).

\section{Data extraction and statistical methods}

The basic feature collection table for studies included was made and filled out, and the data were extracted by two researchers separately. Then, they did a cross-check, and the inconsistencies or disagreements would be solved by them through discussion or by all researchers through consultation. The data extracted included the basic features of the studies (including the name of the first author, the year of publication, the number of cases, the number of cases with flail chest, the number of broken ribs and the follow-up time). Stata version 15.1 software (StatCorp, College Station, TX, USA) was used for the 
Meta-analysis. The test for heterogeneity of the studies included was carried out at first. If no significant heterogeneity among these studies was observed ( $\left.\mathrm{P} \otimes 0.1,1^{2} \llbracket 50 \%\right)$, the fixed effect model was used to analyze the results; if the heterogeneity among these studies was observed ( $\left.\mathrm{P} \otimes 0.1 \otimes \mathrm{l}^{2} \varangle 50 \%\right)$, the random effect model was adopted to analyze the results. Standardized mean difference (SMD) was taken as the statistic for the analysis of continuous variables. The relative risk (RR) was used as the statistic for the analysis of binary variables. $95 \%$ confidence interval $(\mathrm{Cl})$ was used as the interval estimation of each statistic. $0.05(a=0.05)$ was taken as the significant level. That is to say, the difference between the two groups was statistically significant when $\mathrm{P}<0.05$. The analytical results were shown by the forest plots.

\section{Results}

704 papers were retrieved in total, in which 83 papers were selected after excluding 621 papers that were identical and not in line with this study through reading the title and the abstract. After reading the whole article, 78 papers that did not meet the inclusion criteria were excluded and 5 papers were included finally [16-20]. The retrieval process is shown in Fig. 1. The basic features of the articles included are shown in Table 1.

Table 1

Basic characteristics of included studies

\begin{tabular}{|c|c|c|c|c|c|c|c|c|}
\hline \multirow{2}{*}{$\begin{array}{l}\text { Name } \\
\text { Study }\end{array}$} & \multirow[t]{2}{*}{ Year } & \multicolumn{2}{|c|}{ Case } & \multicolumn{2}{|c|}{ Flail chest } & \multicolumn{2}{|c|}{ Number of fractures } & \multirow[t]{2}{*}{ Follow-up } \\
\hline & & 0 & $\mathrm{C}$ & 0 & C & 0 & C & \\
\hline Tanaka [16] & 2002 & 18 & 19 & 18 & 19 & $8.2 \pm 3.3$ & $8.2 \pm 2.6$ & 12 months \\
\hline Granetzny [17] & 2005 & 20 & 20 & 20 & 20 & $\geq 3$ & $\geq 3$ & 2 months \\
\hline Marasco [18] & 2013 & 23 & 23 & 23 & 23 & $11.0 \pm 3.1$ & $11.3 \pm 4.7$ & $3-6$ months \\
\hline Wu [19] & 2015 & 75 & 89 & 31 & 35 & $8.1(6-12)$ & $7.9(6-11)$ & 2 months \\
\hline Liu [20] & 2019 & 25 & 25 & 25 & & Unclear & & Unclear \\
\hline \multicolumn{9}{|c|}{ Notes: O: Operative group C: Conservative group } \\
\hline
\end{tabular}


5 articles [16-20] were included to analyze the respiratory support time (day). The heterogeneity among these 5 studies was observed $\left(I^{2}=94.6 \%, P=0.000<0.1\right)$, so the random effect model was adopted for Meta-analysis. The results indicated that the surgical group had shorter respiratory support time than the conservative group (SMD $=-2.02 ; 95 \% \mathrm{Cl}:-3.22$ to $-0.82 ; \mathrm{P}=0.001<0.05)$, as shown in Fig. 2 .

5 articles [16-20] were included to analyze the intensive care unit (ICU) stay time (day). The heterogeneity among these 5 studies was observed $\left(I^{2}=86.6 \%, P=0.000<0.1\right)$, so the random effect model was adopted for Meta-analysis. The results showed that the surgical group had shorter ICU stay time than the conservative group (SMD $=-1.35 ; 95 \% \mathrm{Cl}:-2.07$ to $-0.64 ; \mathrm{P}=0.000<0.05)$, as shown in Fig. 3 .

3 articles [17-19] were included to analyze the length of stay (day). The heterogeneity among these 3 studies was observed $\left(I^{2}=96.3 \%, P=0.000<0.1\right)$, so the random effect model was adopted for Metaanalysis. The results suggested that the surgical group had shorter length of stay than the conservative group (SMD=-2.77; 95\%Cl: -4.76 to $-0.77 ; \mathrm{P}=0.006<0.05)$, as shown in Fig. 4.

5 articles [16-20] were included to analyze the incidence of pulmonary infection. No significant heterogeneity among these 5 studies was observed $\left(I^{2}=8.9 \%, P=0.356\right)$, so the fixed effect model was used for Meta-analysis. The results showed that the surgical group had lower incidence of pulmonary infection than the conservative group ( $R R=0.48 ; 95 \% \mathrm{Cl}$ : 0.35 to $0.67 ; \mathrm{P}=0.000<0.05)$, as shown in Fig. 5 .

4 articles $[16,18-20]$ were included to analyze the rate of tracheotomy. No significant heterogeneity among these 4 studies was observed $\left(I^{2}=46.7 \%, P=0.131\right)$, so the fixed effect model was used for Metaanalysis. The results indicated that the two groups had almost the same rate of tracheotomy $(R R=0.69$; $95 \% \mathrm{Cl}: 0.45$ to $1.05 ; \mathrm{P}=0.086)$, as shown in Fig. 6 .

4 articles [17-20] were included to analyze the in-hospital mortality. No significant heterogeneity among these 4 studies was observed $\left(I^{2}=0.0 \%, P=0.491\right)$, so the fixed effect model was used for Meta-analysis. The results suggested that the two groups had almost the same in-hospital mortality $(\mathrm{RR}=0.75 ; 95 \% \mathrm{Cl}$ : 0.30 to $1.85 ; P=0.529)$, as shown in Fig. 7.

3 articles $[17,19-20]$ were included to analyze the incidence of chest wall deformity. No significant heterogeneity among these 3 studies was observed $\left(I^{2}=31.6 \%, P=0.232\right)$, so the fixed effect model was used for Meta-analysis. The results showed that the surgical group had lower incidence of chest wall deformity than the conservative group ( $R R=0.07 ; 95 \% \mathrm{Cl}$ : 0.03 to $0.17 ; \mathrm{P}=0.000<0.05)$, as shown in Fig. 8.

2 articles $[16,19]$ were included to analyze the incidence of chest tightness. No significant heterogeneity between these 2 studies was observed $\left(I^{2}=28.8 \%, P=0.236\right)$, so the fixed effect model was used for Meta-analysis. The results showed that the surgical group had lower incidence of chest tightness than the conservative group ( $R R=0.27 ; 95 \% \mathrm{Cl}: 0.17$ to $0.44 ; \mathrm{P}=0.000<0.05)$, as shown in Fig. 9 . 
2 articles $[16,19]$ were included to analyze the incidence of breathlessness on exertion. No significant heterogeneity between these 2 studies was observed $\left(I^{2}=0.0 \%, P=0.337\right)$, so the fixed effect model was used for Meta-analysis. The results showed that the surgical group had lower incidence of breathlessness on exertion than the conservative group $(R R=0.32 ; 95 \% \mathrm{Cl}$ : 0.16 to $0.61 ; P=0.001)$, as shown in Fig. 10 .

\section{Discussion}

Patients with multiple rib fractures often feel strong chest pain in the early stage of injury, so they dare not breathe deeply and cough hard, and the change of their body position will be limited greatly. As time went on, a series of complications like hemothorax, pneumothorax, hemopneumothorax, traumatic coagulopathy, pulmonary infection and respiratory failure occur because of the lack of efficient treatment, thereby threatening their lives and severely affecting the outcome [21-22]. Such patients could only rest in bed, and the hypoxemia caused by acute respiratory failure could only be treated with analgesic drugs, external fixation of chest and respirator in the past [23]. These methods are efficient to a certain extent, but staying in bed for a long time limits the movement of chest and is not conducive to coughing up of sputum, thus leading to complications such as atelectasis and pulmonary infection. Besides, the long intubation time may result in ventilator-associated pneumonia [24-25]. Meanwhile, the conservative treatment often adopts analgesic drugs with a stronger and lasting effect to make patients cough up of sputum. These drugs can reduce the chance of atelectasis and pulmonary infection, but they also make the displacement of the broken end of rib worse, and increase the risk of damaging intercostal vessels and the occurrence of delayed hemothorax caused by fall-off of blood scabs of damaged vessels. As long-term chest pain, chronic pulmonary infection and chest wall deformity are exerting a growing impact on the respiratory function of patients and have reduced the quality of life, the curative effect of conservative treatment is not satisfactory.

The Meta-analysis of this paper indicated that no statistical difference in the rate of tracheotomy and the length of stay between the surgical and conservative groups in treating multiple rib fractures was observed. This might correlate with disease severity, indirectly indicating that the surgery might not increase the occurrence of other complications other than the disease itself. The analytical results also showed that statistical differences in the respirator support time, ICU stay time, length of stay, and the occurrence rates of pulmonary infection, chest wall deformity, chest tightness and breathlessness on exertion were observed, indicating that the surgery was good to the patients with multiple rib fractures.

With so many advantages, the surgical treatment of multiple rib fractures also has negative effects. Firstly, the surgery should be undertaken after general anesthesia, which, however, requires good cardiopulmonary function. The surgery itself causes trauma to the body, and increases the risk in the patients with severe chest injury and with cardiopulmonary injury, but patients with severe chest injury tend to be treated with surgery. Secondly, as internal fixation implants of fractures increase the risk of tissue infection [26], the requirements for the implants are extremely strict. Granetzny [17] have reported 2 cases of wound infection and 2 cases of mediastinal infection after surgery. Thirdly, for some patients who may need secondary surgery, the implant had to be taken out, which increases the pain and the risk. 
Fourthly, the internal fixation may press the intercostal nerves of some patients, who will feel pain and numbness in the corresponding parts of the chest wall, probably reducing their quality of life.

In addition, indications and the timing of surgery for multiple rib fractures also need to be researched. There is no consensus on surgical indications, which depend on the general situation of patients, mainly including unbearable pain at fractured bones, respiratory failure caused by flail chest, the occurrence of chest wall deformity and lung function impairment [27]. In fact, some patients who have multiple and severely dislocated rib fractures do not necessarily have flail chest. They may not feel unbearable pain and have respiratory failure when they breathe slowly and stay in bed, but they also need surgery considering the high incidence of atelectasis, pulmonary infection and chest wall deformity in them. In addition, hemodynamic instability like the progressive hemothorax and delayed hemothorax, is also one of the indications of surgical treatment. Therefore, the change degree of chest volume within 24-48 hours, the dislocation degree of fracture end and the influence on the respiratory function should be considered when we assess whether a patient with multiple rib fractures should be treated surgically or non-surgically [5]. The timing of surgery is not unified at present. Some studies claim that the surgery should be performed within 24 hours or 8 days[28]. Though there is no clear consensus on the timing of surgery, it is commonly believed that the sooner to perform a surgery, the better for the patients. In theory, early surgical intervention can avoid prolonging the use of respirator and decrease the related complications for patients with multiple rib fractures and flail chest, while putting off surgery may cause these benefits to disappear and even greatly increase the incidence of complications [29], as proved by the Meta-analysis results of this paper. When to perform a surgery on patients with chest trauma, combined injuries and multiple injuries is also worth thoroughly pondering. No consensus on the indications and the timing of the surgery for multiple rib fractures makes the surgical treatment of rib fractures always a controversial topic, and only through the comprehensive assessment and consideration can the patients benefit more from the surgery. Briefly, as the fast tract surgery theory and damage control surgery are developing rapidly and widely applied in the field of chest surgery [30-31], the research on rib fractures has gradually deepened, the standardized treatment plan is made and the research on internal fixation materials tends to mature, it is believed that the surgical treatment of multiple rib fractures can gradually be accepted by doctors and patients and get the treatment value it deserves.

This study has some limitations. Firstly, a small number of samples were included and there are some confounding factors in two groups of data, such as whether the flail chest influences the assessment of the curative effect. Secondly, limited by ethics, it is hard to design high-quality randomized controlled trials, especially the double-blind trials. Thirdly, the lack of long-term continuous follow-up data in this research field will also affect the assessment of the clinical effect of the surgical group.

\section{Conclusion}

The Meta-analysis of this study shows that the surgical group is superior to the conservative group in respirator support time, ICU stay time, length of stay, and the incidence of pulmonary infection, chest wall 
deformity, chest tightness and breathlessness on exertion, indicating that the surgical treatment of multiple rib fractures can shorten the respirator support time, ICU stay time and length of stay, and lower the incidence of pulmonary infection and chest disability. However, this conclusion needs to be further verified by more randomized controlled trials.

\section{Abbreviations}

RCT: randomized controlled trials; ICU: intensive care unit; SMD: Standardized mean difference; RR: relative risk; $\mathrm{Cl}$ : confidence interval.

\section{Declarations}

\section{Acknowledgements}

Not applicable.

\section{Authors' contributions}

Study conception and design: HZ. Data collection and analysis: HZ and TF. All authors evaluated the included studies. Article writing: HZ. All authors read and approved the final manuscript.

\section{Funding}

Not applicable.

\section{Availability of data and materials}

Not applicable.

\section{Ethics approval and consent to participate}

Not applicable.

\section{Consent for publication}

Not applicable.

\section{Competing interests}

The authors declare that they have no competing interests.

\section{Author details}

1Department of Thoracic Surgery, Tianjin Xiqing Hospital, Xiqing Road No.403, Yangliuqing, Xiqing District, Tianjin 300380, China 
2 Medical Imaging Center, Tianjin Xiqing Hospital, Xiqing Road No.403, Yangliuqing, Xiqing District, Tianjin 300380, China

\section{References}

1. Marasco S, Lee G, Summerhayes R, Fitzgerald M, Bailey M. Quality of life after major trauma with multiple rib fractures. Injury. 2015;46(1):61-5.

2. Xu JQ, Qiu PL, Yu RG, Gong SR, Ye Y, Shang XL. Better short-term efficacy of treating severe flail chest with internal fixation surgery compared with conservative treatments. Eur J Med Res. 2015;20:55.

3. Veysi VT, Nikolaou VS, Paliobeis C, Efstathopoulos N, Giannoudis PV. Prevalence of chest trauma, associated injuries and mortality: a level I trauma centre experience. Int Orthop. 2009;33(5):1425-33.

4. Jayle CP, Allain G, Ingrand P, Laksiri L, Bonnin E, Hajj-Chahine J, et al. Flail chest in polytraumatized patients: surgical fixation using Stracos reduces ventilator time and hospital stay. Biomed Res Int. 2015;2015:624723.

5. Vana PG, Neubauer DC, Luchette FA. Contemporary management of flail chest. Am Surg. 2014;80(6):527-35.

6. Velasquez M, Ordoñez CA, Parra MW, Dominguez A, Puyana JC. Operative versus Nonoperative Management of Multiple Rib Fractures. Am Surg. 2016;82(5):e103-5.

7. Majercik S, Vijayakumar S, Olsen G, Wilson E, Gardner S, Granger SR, et al. Surgical stabilization of severe rib fractures decreases incidence of retained hemothorax and empyema. Am J Surg. 2015;210(6):1112-6 discussion 1116-7.

8. Schulte $K$, Whitaker $D$, Attia R. In patients with acute flail chest does surgical rib fixation improve outcomes in terms of morbidity and mortality? Interact Cardiovasc Thorac Surg. 2016;23(2):314-9.

9. Pieracci FM, Lin Y, Rodil M, Synder M, Herbert B, Tran DK, et al. A prospective, controlled clinical evaluation of surgical stabilization of severe rib fractures. J Trauma Acute Care Surg. 2016;80(2):187-94.

10. Su YH, Yang SM, Huang $\mathrm{CH}$, Ko HJ. Early versus late surgical stabilization of severe rib fractures in patients with respiratory failure: A retrospective study. PLoS One. 2019;14(4):e0216170.

11. Girsowicz E, Falcoz PE, Santelmo N, Massard G. Does surgical stabilization improve outcomes in patients with isolated multiple distracted and painful non-flail rib fractures? Interact Cardiovasc Thorac Surg. 2012;14(3):312-5.

12. Ingoe HM, Coleman E, Eardley W, Rangan A, Hewitt C, McDaid C. Systematic review of systematic reviews for effectiveness of internal fixation for flail chest and rib fractures in adults. BMJ Open. 2019;9(4):e023444.

13. Liu $X$, Xiong K. Surgical management versus non-surgical management of rib fractures in chest trauma: a systematic review and meta-analysis. J Cardiothorac Surg. 2019;14(1):45. 
14. Kasotakis G, Hasenboehler EA, Streib EW, Patel N, Patel MB, Alarcon L, et al. Operative fixation of rib fractures after blunt trauma: A practice management guideline from the Eastern Association for the Surgery of Trauma. J Trauma Acute Care Surg. 2017;82(3):618-26.

15. Schuurmans J, Goslings JC, Schepers T. Operative management versus non-operative management of rib fractures in flail chest injuries: a systematic review. Eur J Trauma Emerg Surg. 2017;43(2):1638.

16. Tanaka H, Yukioka T, Yamaguti Y, Shimizu S, Goto H, Matsuda H, et al. Surgical stabilization of internal pneumatic stabilization? A prospective randomized study of management of severe flail chest patients. J Trauma. 2002;52(4):727-32 discussion 732.

17. Granetzny A, Abd El-Aal M, Emam E, Shalaby A, Boseila A. Surgical versus conservative treatment of flail chest. Evaluation of the pulmonary status. Interact Cardiovasc Thorac Surg. 2005;4(6):583-7.

18. Marasco SF, Davies AR, Cooper J, Varma D, Bennett V, Nevill R, et al. Prospective randomized controlled trial of operative rib fixation in traumatic flail chest. J Am Coll Surg. 2013;216(5):924-32.

19. Wu WM, Yang Y, Gao ZL, Zhao TC, He WW. Which is better to multiple rib fractures, surgical treatment or conservative treatment? Int J Clin Exp Med. 2015;8(5):7930-6.

20. Liu T, Liu P, Chen J, Xie J, Yang F, Liao Y. A Randomized Controlled Trial of Surgical Rib Fixation in Polytrauma Patients With Flail Chest. J Surg Res. 2019;242:223-30.

21. Topcu I, Ekici Z, Sakarya M. Comparison of clinical effectiveness of thoracic epidural and intravenous patient-controlled analgesia for the treatment of rib fractures pain in intensive care unit. Ulus Travma Acil Cerrahi Derg. 2007;13(3):205-10.

22. Dehghan N, de Mestral C, McKee MD, Schemitsch EH, Nathens A. Flail chest injuries: a review of outcomes and treatment practices from the National Trauma Data Bank. J Trauma Acute Care Surg. 2014;76(2):462-8.

23. Karmakar MK, Ho AM. Acute pain management of patients with multiple fractured ribs. J Trauma. 2003;54(3):615-25.

24. Brasel KJ, Guse CE, Layde P, Weigelt JA. Rib fractures: relationship with pneumonia and mortality. Crit Care Med. 2006;34(6):1642-6.

25. Fagevik Olsén M, Slobo M, Klarin L, Caragounis EC, Pazooki D, Granhed H. Physical function and pain after surgical or conservative management of multiple rib fractures - a follow-up study. Scand $\mathrm{J}$ Trauma Resusc Emerg Med. 2016;24(1):128.

26. Carbognani P, Cattelani L, Bellini G, Rusca M. A technical proposal for the complex flail chest. Ann Thorac Surg. 2000;70(1):342-3.

27. Lafferty PM, Anavian J, Will RE, Cole PA. Operative treatment of chest wall injuries: indications, technique, and outcomes. J Bone Joint Surg Am. 2011;93(1):97-110.

28. Borrelly J, Aazami MH. New insights into the pathophysiology of flail segment: the implications of anterior serratus muscle in parietal failure. Eur J Cardiothorac Surg. 2005;28(5):742-9. 
29. Leinicke JA, Elmore L, Freeman BD, Colditz GA. Operative management of rib fractures in the setting of flail chest: a systematic review and meta-analysis. Ann Surg. 2013;258(6):914-21.

30. Dumans-Nizard V, Guezennec J, Parquin F, Puyo P, Sage E, Abdat R, et al. Feasibility and results of a fast-track protocol in thoracic surgery. Minerva Anestesiol. 2016;82(1):15-21.

31. Loop T. Fast track in thoracic surgery and anaesthesia: update of concepts. Curr Opin Anaesthesiol. 2016;29(1):20-5.

\section{Figures}

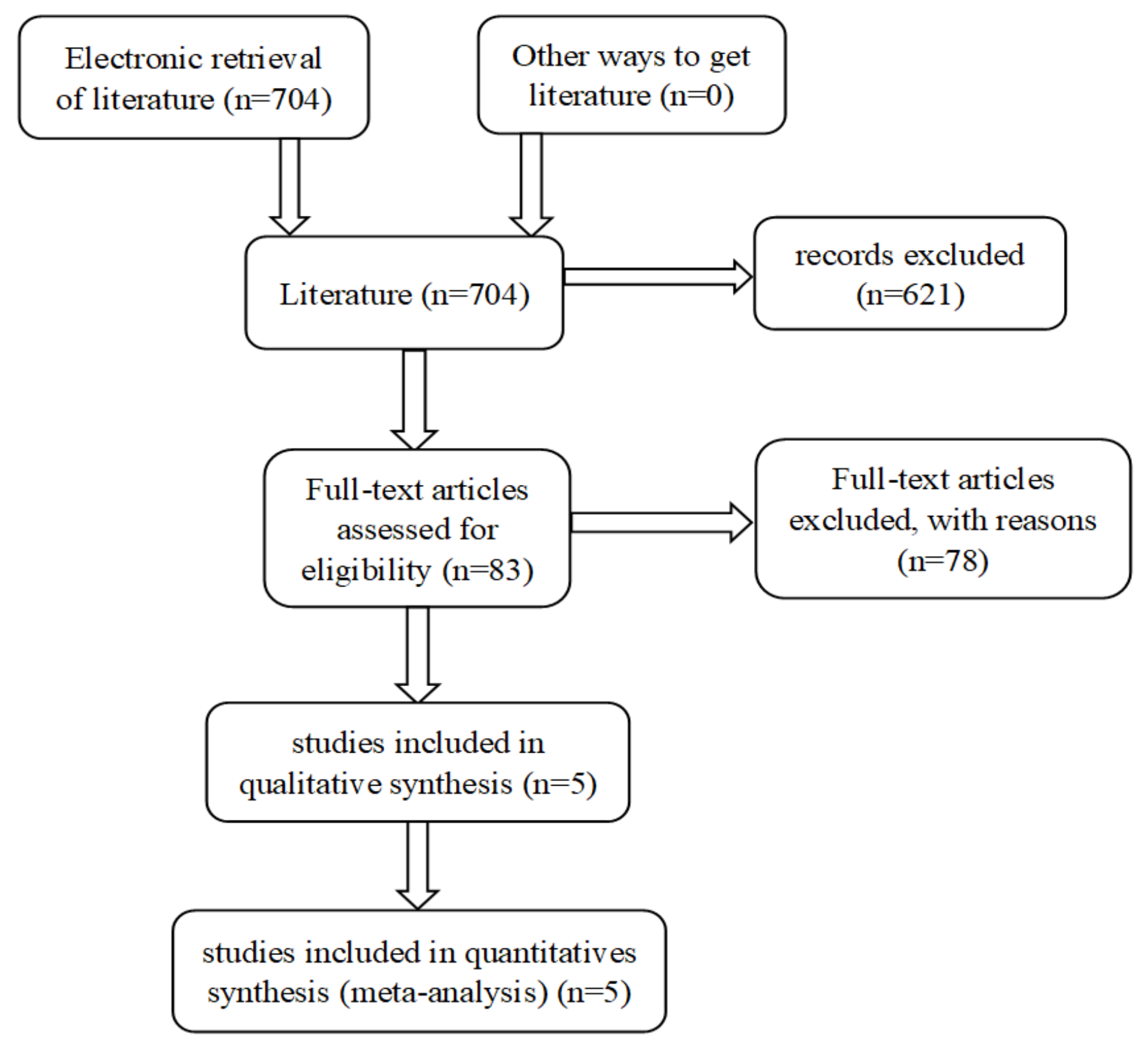

Figure 1 
Study

ID

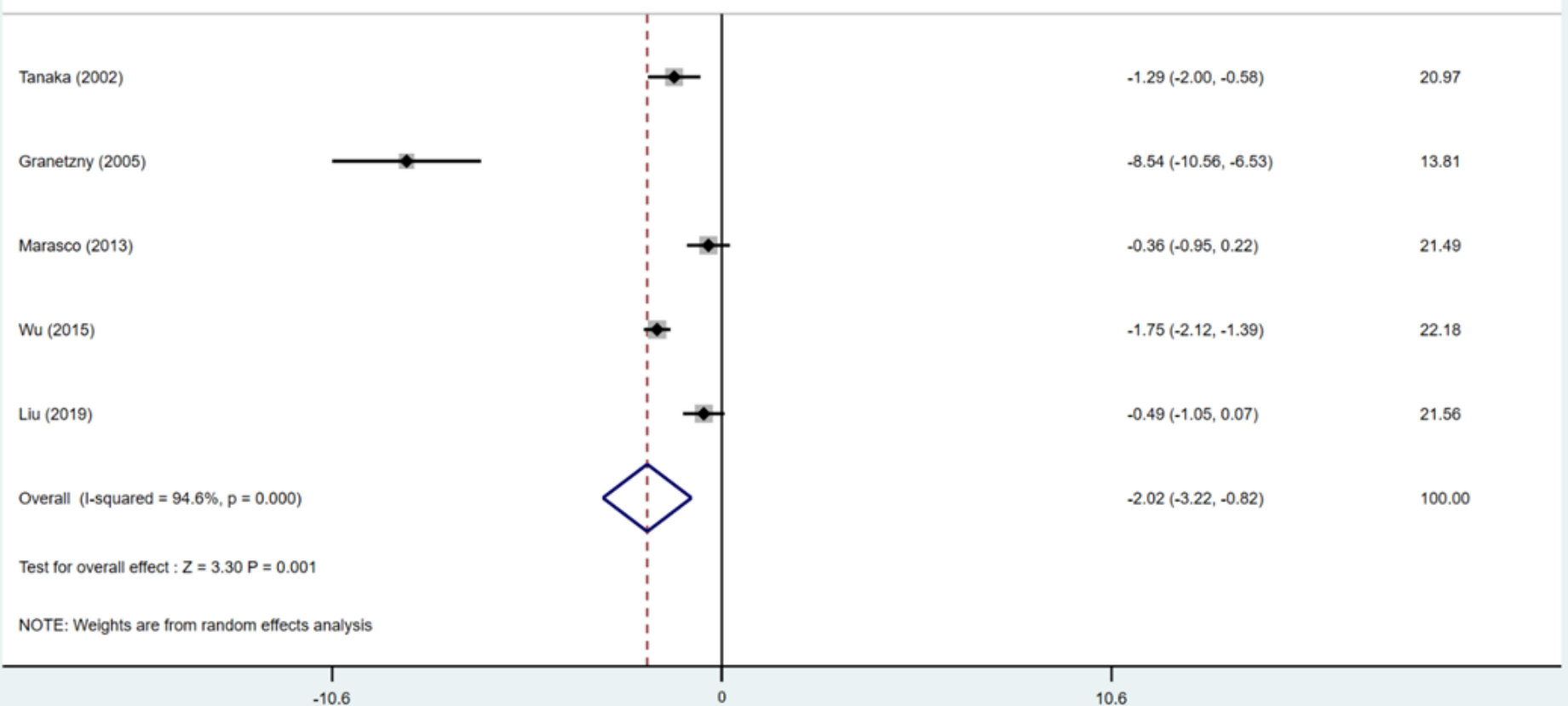

\section{Figure 2}

Forest plot of respiratory support time (day) 
SMD $(95 \% \mathrm{Cl})$

Weight

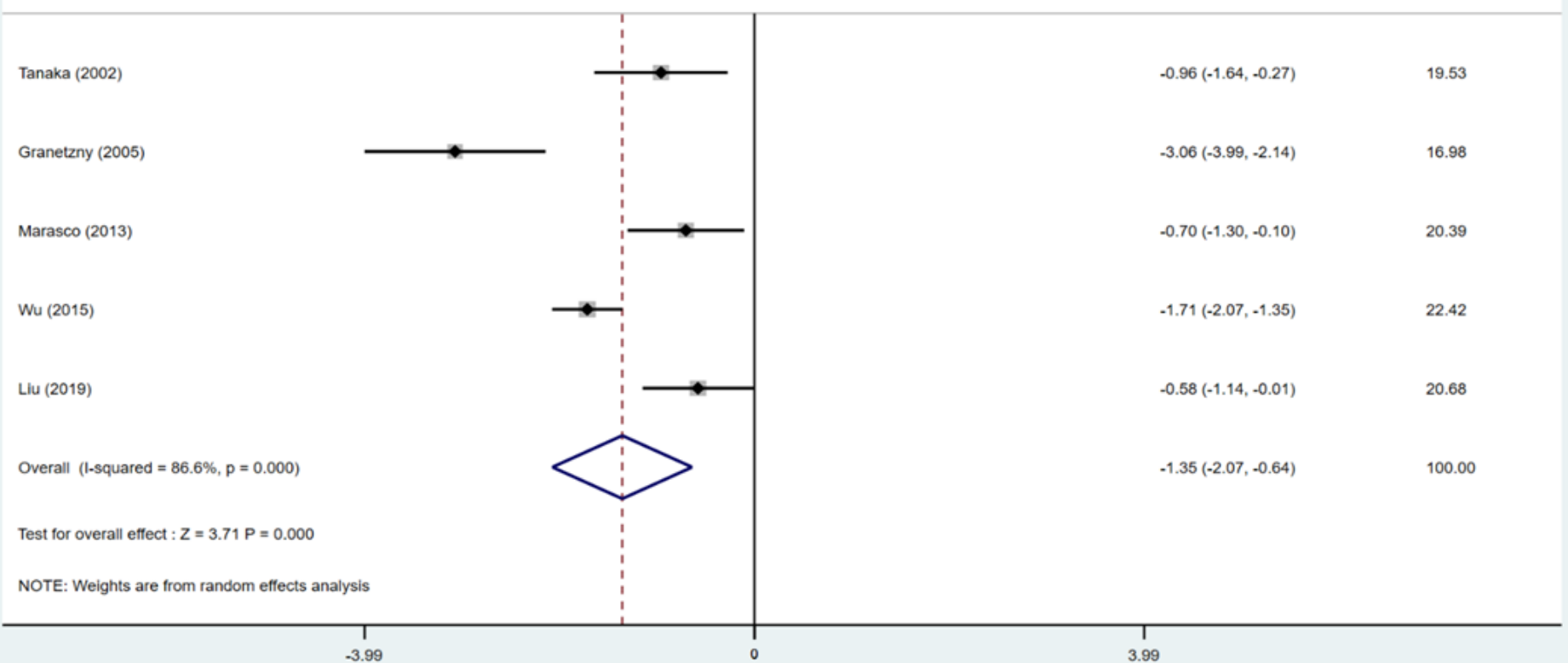

\section{Figure 3}

Forest plot of ICU stay time (day) 


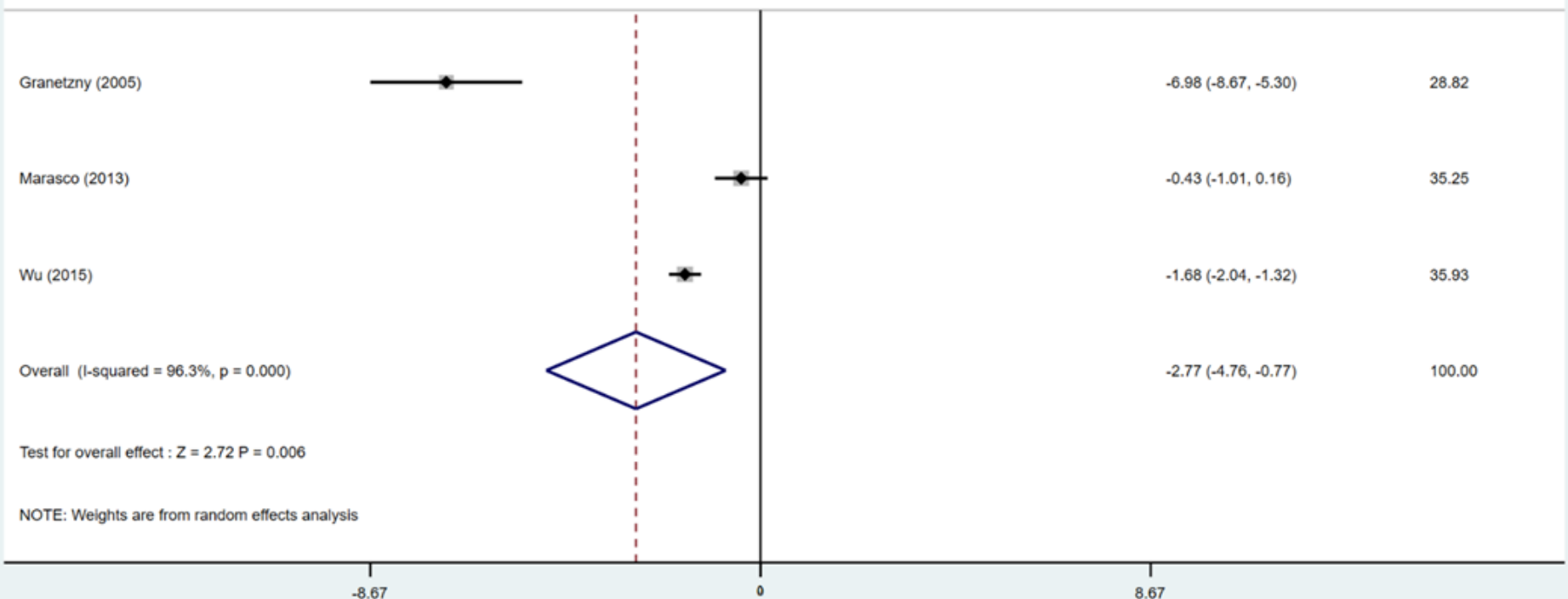

Figure 4

Forest plot of length of stay (day) 


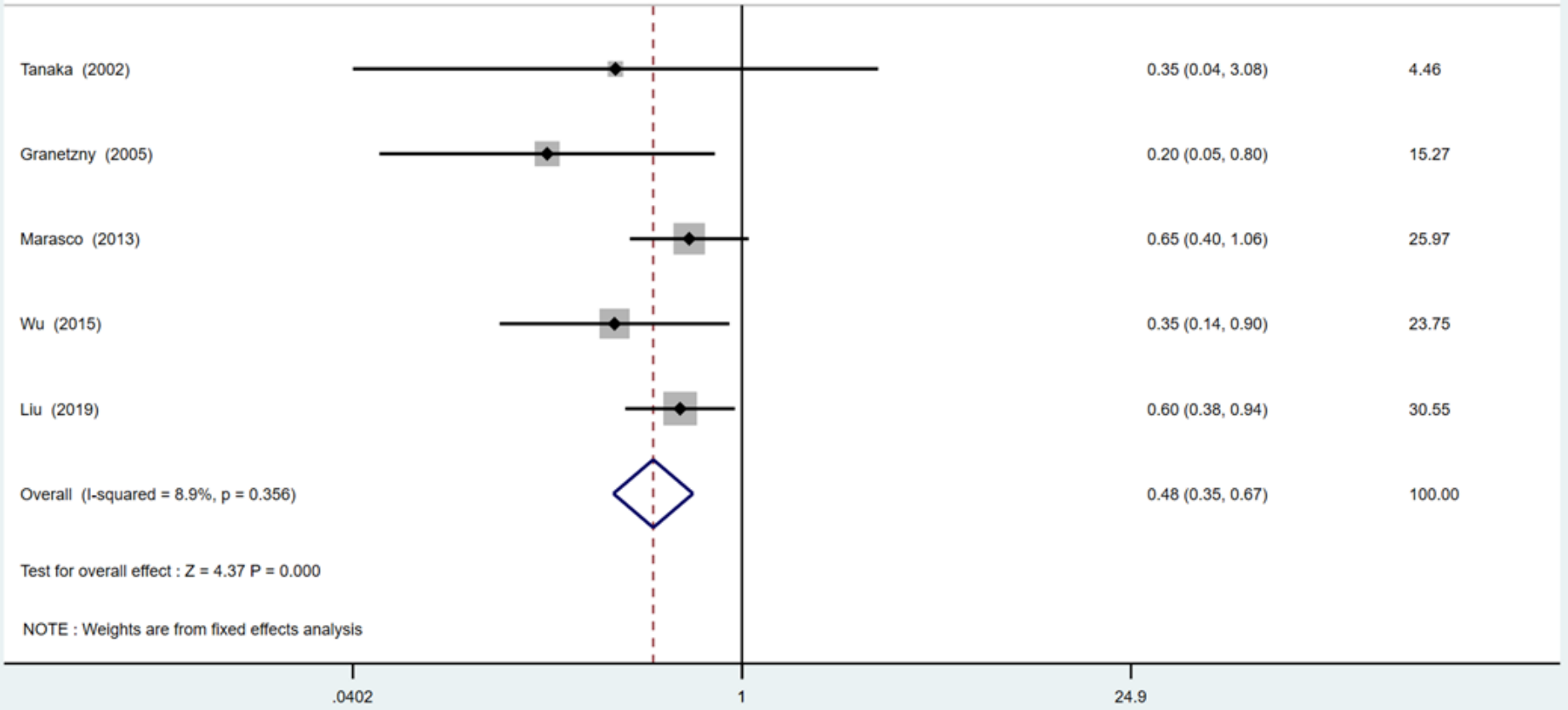

\section{Figure 5}

Forest plot of incidence of pulmonary infection 
RR $(95 \% \mathrm{Cl})$

Weight

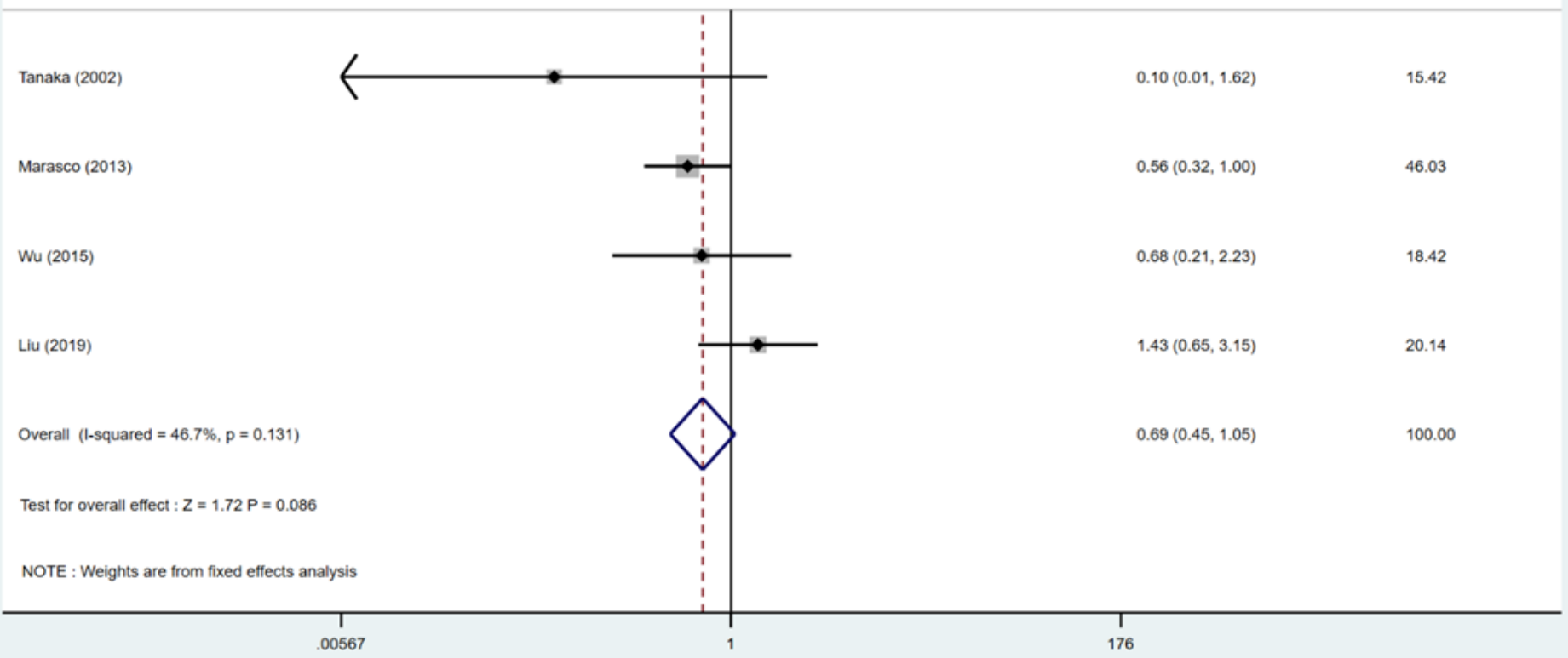

Figure 6

Forest plot of rate of tracheotomy 


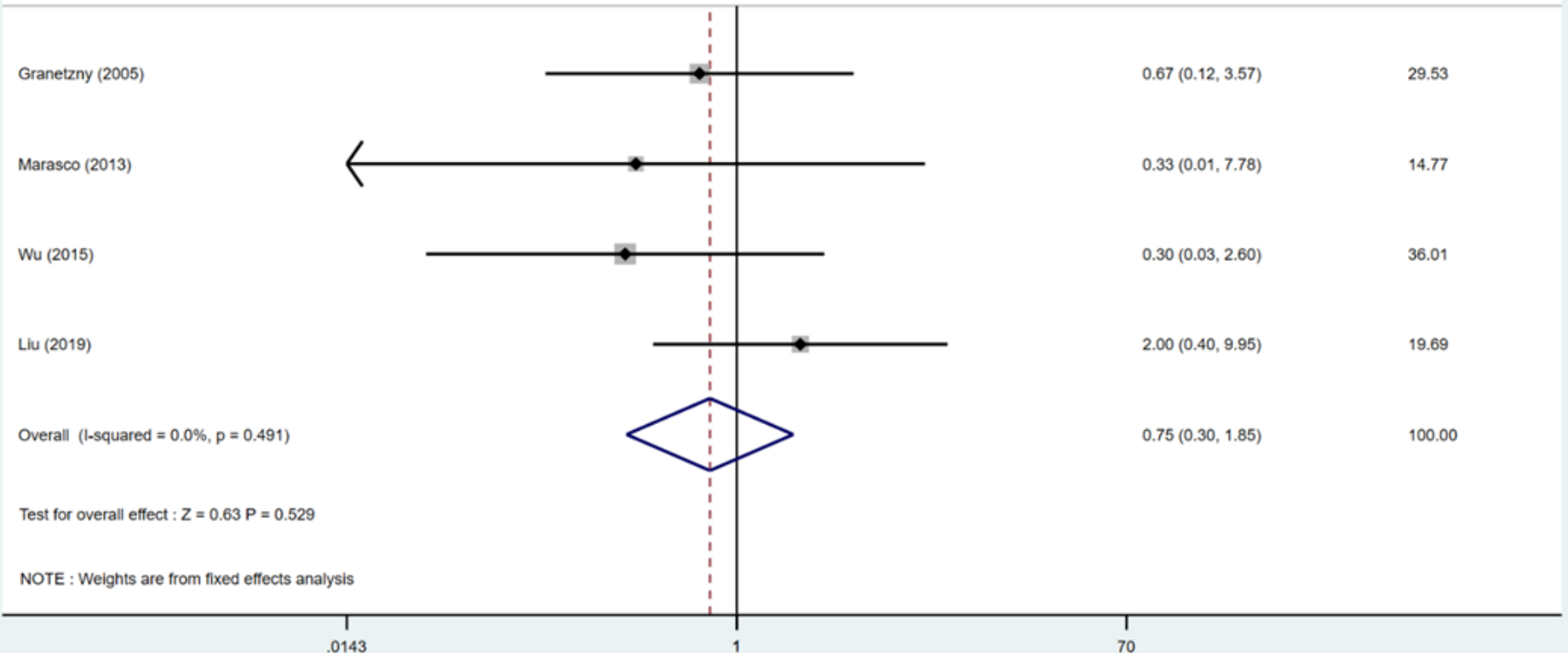

Figure 7

Forest plot of in-hospital mortality 


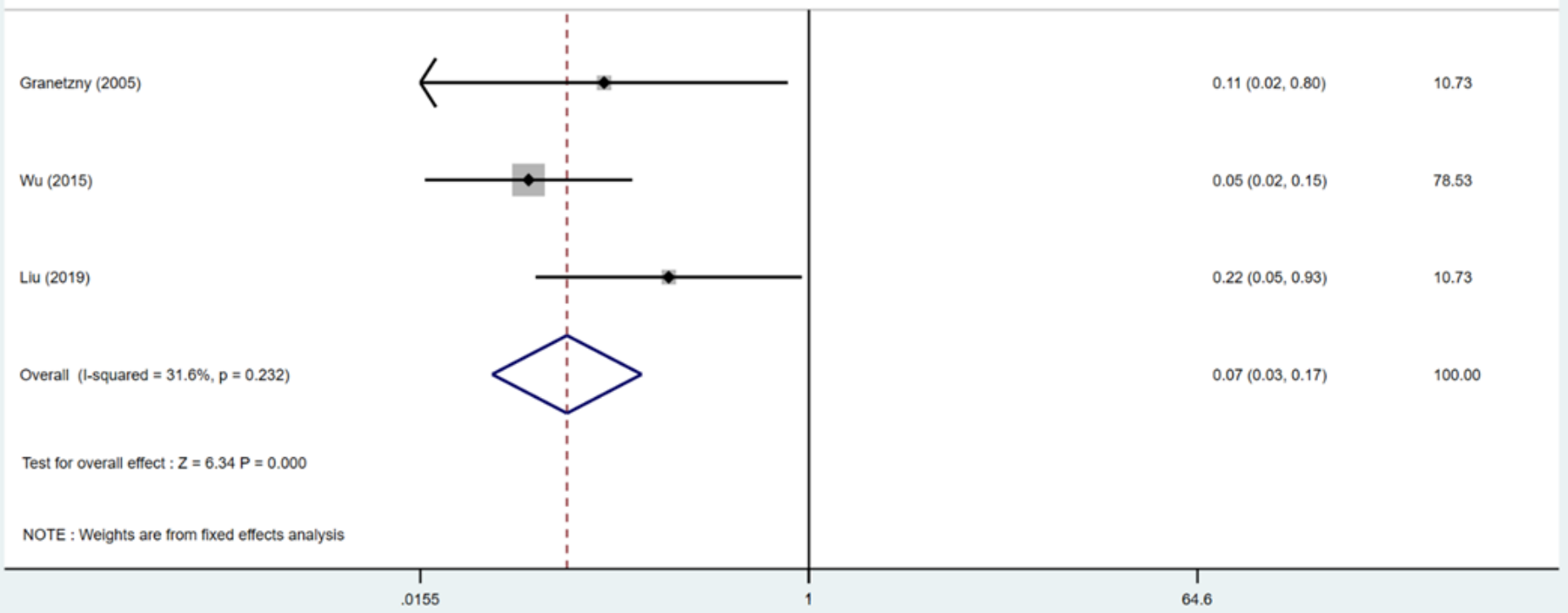

\section{Figure 8}

Forest plot of incidence of chest wall deformity 


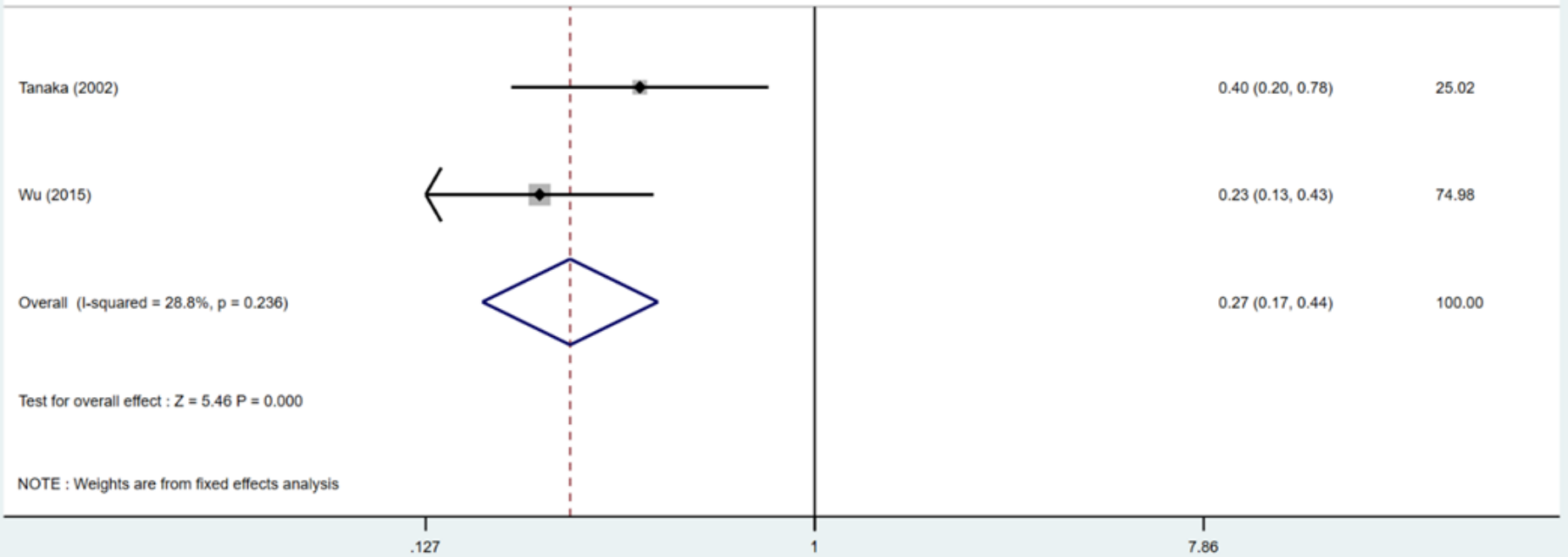

Figure 9

Forest plot of incidence of chest tightness 


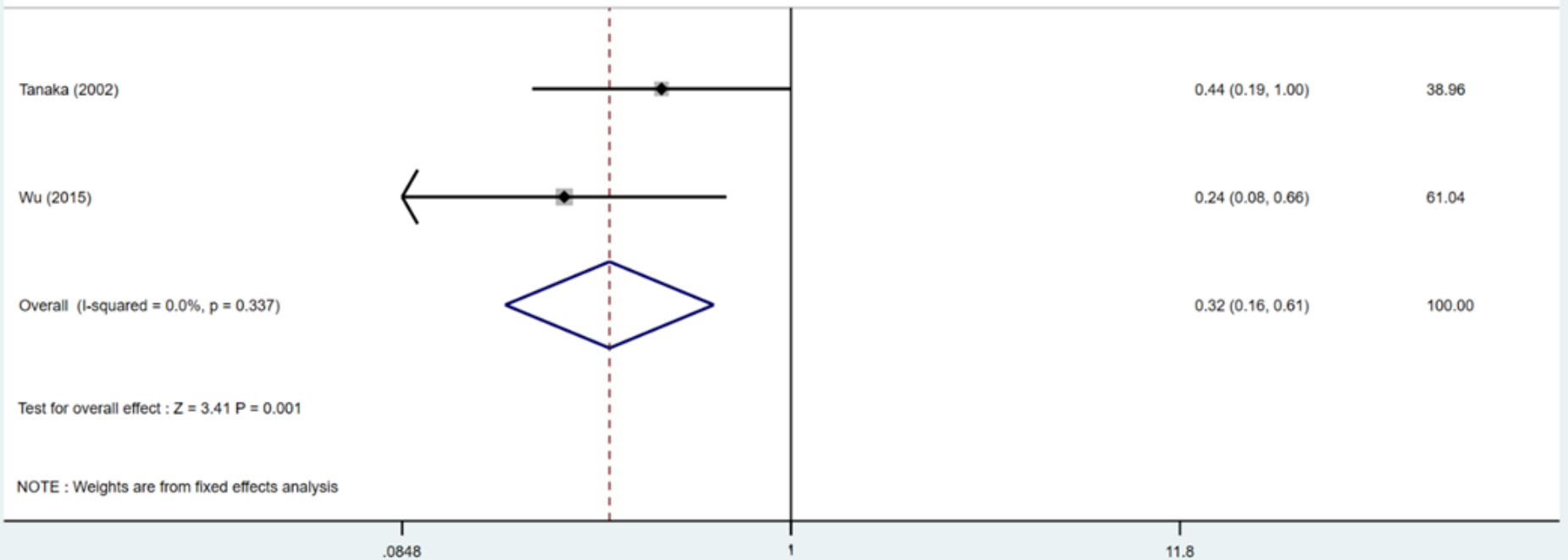

Figure 10

Forest plot of incidence of breathlessness on exertion 